\title{
Effects of anxiety and stress on verbal mediation in children'
}

\author{
Joyee Ching-Yi Wu and Lewis P. Lipsitt \\ BROWN UNIVERSITY
}

\begin{abstract}
Effects of test-defined anxiety and instruction-induced stress on verbal mediation were investigated in 58 fifth grade children, under the expectation that increases in drive level would enhance both mediated facilitation and interference. Both facilitation and interference were obtained, but anxiety and stress tended to increase errors on all types of word pairs, including nonmediational control pairs.

\section{Introduction}

Wismer \& Lipsitt (1964) demonstrated both mediated facilitation and interference effects, concurrently in the same Ss, in a verbal paired associate experiment. This was accomplished in a three-list situation by administering word pairs under (1) an $\mathrm{A}-\mathrm{B}, \mathrm{B}-\mathrm{C}, \mathrm{A}-\mathrm{C}$ paradigm for facilitation pairs, (2) an A-B, B-C, A-C reversed paradigm for interference pairs, (3) an $A-B$, $\mathrm{X}-\mathrm{C}, \mathrm{A}-\mathrm{C}$ procedure for one type of control pair, and (4) new word pairs for another type of control.

The present study was run under identical conditions, except for the introduction of procedures for heightening drive level of some of the Ss. Spence (1956, pp. 224235) has hypothesized, and presented data to substantiate, that increases in drive level facilitate learning of word pairs of high associative relationship to one another, but that such drive-increases impair the learning of competitional word pairs in which the response to be learned to a given stimulus has a lesser probability of occurrence than some other response to that stimulus.

From the assumption of such an interactive relationship between relative S-R strengths and drive condition, the present study predicted that anxiety and stress would increase the initial strengths of all third-list S-R tendencies, and thus would enhance performance (reduce errors) on mediated facilitation pairs and impair performance (increase errors) on mediated interference pairs, both of these effects to occur relative to performance on control pairs.
\end{abstract}

\section{Method}

The stimulus materials, method of presenting these, and general procedures were the same as those used by Wismer \& Lipsitt (1964). The Ss were 58 fifth grade boys and girls. The stimulus and stimulus-response slides were presented by automatic slide projector and the Ss responded orally. Three groups of Ss, a high anxiety, a high stress, and a control (low anxiety, low stress) resulted from the following procedure:

Each $\mathrm{S}$ was given a short form of the Children's Manifest Anxiety Scale (Levy, 1958) independently as he appeared in the experimental room. The Ss were sent to the experimental room in no systematic, and presumably random, order by the teacher. The anxiety score was tallied immediately after the $S$ finished answering the items and was the number of items, of 10 , answered "Yes." The Ss were assigned to one of three groups depending upon the anxiety-score obtained. In the present experiment, about half $(\mathrm{N}=18)$ of the $\mathrm{Ss}$ who scored in the 3-6 range were subsequently administered the stress instructions, and thus became the Stress Group. The remaining $40 \mathrm{Ss}$ were administered identical instructions and treatment throughout, but approximately half $(\mathrm{N}=19)$ of these were high scorers (Anxiety Score $=6-10$ ) and are hereinafter referred to as the Anxiety Group, and the rest $(\mathrm{N}=21$ ) were low scorers (Anxiety Score $=0-5$ ) and are considered the Control Group.

The two treatments differed only in the exposure time of each word-slide on List III. The Control and Anxiety Groups had a 5-sec. exposure of each slide (stimulus and stimulus-response), and a $10-\mathrm{sec}$. interval between presentations of each word list. The Stress Group had the same exposure time for each slide on Lists I and II, but exposure time was reduced to $2 \mathrm{sec}$. on List III. This reduction of stimulus presentation time reduced the time permitted for the child to make a response and noticeably increased tension, alterness, or vocal intensity.

\section{Results}

As in the previous study, the numbers of List III errors for the different kinds of word pairs were analyzed. Table 1 presents the error data for the three groups. Since the two types of control pairs did not differ in error frequency in the present experiment, these were combined to provide one Control-pair error score. It may be seen that, for all Ss combined, fewer facilitationpair errors were made than control-pair errors, and more interference-pair errors were made than controlpair errors. Both of these effects were reliable $(t=2.82$ and 13.38 respectively; $d f=57 ; p<.01$ ) and replicate the mediational effects of Wismer \& Lipsitt (1964). The hypothesis regarding the differential effects of presumed increases in drive-level, however, fared less well, Errors of all types were increased in the Anxiety and Stress Groups relative to the Control Group. These error increases were reliable for all types of word-pair for the Stress Group $(t=3.20,2.07,3.80 ; d f=37 ; p<.01$, $.05, .001$ for Control-pair, Facilitation-pair, and Interference-pair, respectively), while none of these comparable comparisons was reliable for the Anxiety Group $(t=1.34,1.68,1.58 ; \mathrm{df}=38)$. 
Table 1

Number of Errors for Different Pair-types and the Three Groups

\begin{tabular}{|c|c|c|c|c|c|c|c|c|}
\hline \multirow{3}{*}{$\begin{array}{l}\text { Number Errors } \\
\text { by Pair Type }\end{array}$} & \multicolumn{2}{|c|}{ Control } & \multicolumn{2}{|c|}{ Anxiety } & \multicolumn{2}{|c|}{ Stress } & \multicolumn{2}{|c|}{ Total } \\
\hline & A-Score & $0-5$ & A-Score & $6-10$ & A-Score & $3-6$ & & \\
\hline & Mean & $\mathrm{SD}$ & Mean & $S D$ & Mean & SD & Mean & $S D$ \\
\hline Facilitation & 4.14 & 2.23 & 5.53 & 2.85 & 6.50 & 4.48 & 5.33 & 3.41 \\
\hline Interference & 10.81 & 5.15 & 13.32 & 4.60 & 16.89 & 4.50 & 13.52 & 5.39 \\
\hline Control & 4.98 & 2.03 & 6.00 & 2.65 & 8.56 & 4.51 & 6.42 & 3.51 \\
\hline Total Errors & 19.93 & & 24.85 & & 31.95 & & 25.27 & \\
\hline $\mathbf{N}$ & & & & & & & & \\
\hline
\end{tabular}

\section{Diseussion}

The present data replicate the mediational facilitation and interference effects found by Wismer and Lipsitt, but do not support the proposition that increased anxiety or stress will increase such effects. Rather, all types of errors were increased by anxiety and stress, significantly so for the latter condition. Additional statistical analyses based on percentages of facilitation-pair and and interference-pair errors relative to control-pair errors did not reveal any differential effect of increased drive-level on the various pair-types. While it appears on the basis of these data that the interaction assumption of Spence may not apply to word-pair response hierarchies induced through successive-list mediational procedures, additional studies are required which will increase the drive differences between the Control Group and the Anxiety and Stress Groups. The present study may have minimized the likelihood of confirming the interaction hypothesis by allowing anxiety scores in the Stress Group to overlap those of the Control Group, and by not using a more marked anxiety-score dichotomy in the Anxiety and Control Groups. In connection with the latter point, it may be noted that mean errors of all types in the present Control Group agree very well with those of the Wismer-Lipsitt study in which all kinds of Ss, high and low anxiety, were combined. It is possible that the anxiety effects would have been enhanced were the Control Group of a more markedly low anxiety level.

Relerences

CAstaneda, A., McCAndless, B. R., \& PAlermo, D. S. The children's form of the Manifest Anxiety Scale. Child Develpm., $1956,27,317-326$.

LEVY, N. A short form of the Children's Manifest Anxiety Scale. Child Develpm., 1958, 29, 153-154.

SPENCE, K. W. Behavior Theory and Conditioning. New Haven: Yale University Press, 1956.

WISMER, BETTY, \& LIPSITT, L. P. Verbal mediation in paired associate learning. J. exp. Psychol., 1964, 68, 441-448.

\section{Note}

1. This study was made possible, in part, by an NSF grant (G-9681) to Lewis P. Lipsitt for the study of children's discrimination learning. Thanks are due Miss Florence McGwin, principal of the Summit Avenue School, Providence. 